\title{
Aproximación a los desafíos para la aplicación de la Ley de Ordenamiento Territorial y Desarrollo Sostenible. Derecho de propiedad, seguridad y certeza jurídica en el marco de la ley
}

\author{
Approaching the law enforcement challenges of the Territorial \\ Ordering and Sustainable Development Law. Right of property, \\ security and legal certainty from a law perspective
}

\section{Myriam D. Miranda Camacho*}

\footnotetext{
* Escribana pública y procuradora. Integrante de la Cátedra de Medio Ambiente y Ordenamiento Territorial y de la Cátedra de Técnica IV (Derecho Civil) de la Facultad de Derecho de la Universidad CLAEH.

$凶$ escribanammirandacamacho@ gmail.com
}

\begin{abstract}
Resumen
Esta investigación refiere al derecho de propiedad en Uruguay, entendido y consagrado como derecho fundamental e integrante del elenco de otros derechos, deberes y garantías de los habitantes de la república, así como a su relevancia social y territorial, junto con otros derechos de la persona protegidos por la Constitución y la ley. Se pretendió analizar la legislación del ordenamiento territorial que, con distintos nombres a través de la historia, hoy integra los antecedentes de la primera Ley de Ordenamiento Territorial y Desarrollo Sustentable del Uruguay, del 18 de junio de 2008. Varias leyes aprobadas, del siglo XIX y del siglo XX, regularon sobre la materia. Se consideró si las reglas que regulan nuestra propiedad territorial deberán permanecer inalteradas en la sociedad del siglo XXI, como las definió el Código Civil del siglo XIX con las adiciones del siglo XX, o deberán ser actualizadas.
\end{abstract}

Palabras clave: desarrollo sostenible, planificación regional, legislación, Uruguay. 


\begin{abstract} century with the additions of the 20th century, or should be updated.

\section{Presentación \\ Una mirada humanista en el método de la investigación Fr. Louis Joseph Lebret}

This investigation refers to the social and territorial relevance of the property right in Uruguay, understood and consecrated as fundamental among other rights, duties and guarantees of the inhabitants of the Uruguayan Republic. It intends to analyze territorial legislation, under different names throughout history, exploring the backgrounds of the first Law of Territorial Ordering and Sustainable Development of the country, of June 18th, 2008. Several laws approved during the XIX and XX centuries ruled on this matter. It is questioned whether the current rules that govern territorial property for a 21st Century society should remain in full force, as defined by a Civil Code of the 19th

Keywords: sustainable development, regional planning, legislation, Uruguay.

En la década del cuarenta, el gran humanista y economista Fr. Louis Joseph Lebret, en su obra Dinámica concreta del desarrollo, hacía referencia al centro de estudios Économie et Humanisme (Economía y Humanismo) y a los métodos de investigación utilizados en distintos países, rigurosos en la investigación, de compromiso humanista e innovación en el conocimiento:

Este centro de estudios nació del sentimiento de que era posible dirigir una evolución técnica y económica en un sentido favorable a los hombres, si se empezaba por estudiar la realidad compleja que se debe dominar, si se elaboraba una doctrina y si se creaban las fuerzas colectivas deseosas de aplicarla. (Lebret, 1960)

En septiembre de 1952, Économie et Humanisme celebraba una semana de estudios para especialistas cuyos principales puntos quedaron expuestos en el Cuaderno n. ${ }^{79}$, sobre la organización de los territorios, junto con una especie de mapa de la organización, resumen de las conclusiones de la sesión. Desde las primeras publicaciones, se había llamado la atención sobre la importancia de la organización regional.

En 1953, una sesión sobre la economía de las necesidades (Cuaderno n. ${ }^{\circ}$ 84, de marzo-abril de 1954) permitió profundizar en la noción de necesidad y precisar sus variedades. 
Querríamos que fuese una de las aportaciones de las que pueda obtener algún provecho la disciplina del desarrollo. [...] nuestra actuación está en la línea de estudio que conducirá lentamente a hacer de esta disciplina lugar de convergencia de tantas otras que se enlazan con ella, una de las más importantes elaboraciones científicas y prácticas de la segunda mitad del siglo Xx. (Lebret, 1960, prólogo)

\section{Primera parte}

\section{Una mirada hacia el ordenamiento territorial}

El término territorio, proveniente del latín, siempre refirió a una extensión determinada de la superficie terrestre sobre la cual vive un grupo humano. A partir del siglo XVIII, con las obras de Montesquieu y Rousseau, pasó a designarse de ese modo una extensión de tierra donde habita una colectividad humana con una autoridad definida.

La Constitución uruguaya, en su primer artículo, define a la República como «la asociación política de todos los habitantes comprendidos dentro de su territorio» (Semino, anot., 1997). Según esta definición, nuestro habitar en el mundo se fundamenta en el grupo humano que somos, en la asociación que conformamos y en el territorio que nos comprende.

El territorio, por lo tanto, incluye a los habitantes, y estos conforman una asociación política que por naturaleza los hace existir como colectivo en ese territorio en el país.

Aparecen claramente en esta definición dos proyecciones fundamentales del concepto: aquella que define a los habitantes en función de su pertenencia a un territorio definido y aquella que los hace asociarse políticamente, dándoles un modo de existencia colectiva que se vincula al propio territorio.

La Constitución de la República, en su artículo 4. ${ }^{\circ}$, reconoce en el territorio nacional uno de los elementos constitutivos de su existencia y lo asume como el soporte material de la soberanía. El territorio nacional refiere a un área de la superficie terrestre con límites precisos sobre la cual los habitantes de la República, como hecho colectivo, ejercen su autoridad.

El artículo 4 de la Constitución consagra: «La soberanía en toda su plenitud existe radicalmente en la Nación, a la que compete el derecho exclusivo de establecer sus leyes» (Semino, anot., 1997). Destacan también aquí el soporte material, los habitantes y la relación que los une y los legitima en ese lugar preciso de la superficie terrestre. 
El concepto de soberanía, entonces, trasciende lo meramente individual para conformarse como derecho político de todos los habitantes sobre la porción de suelo que reconocen como propia.

Junto con la población, el Gobierno y la capacidad para entrar en relaciones con otros Estados, la determinación del territorio es uno de los elementos que, también fuera del ámbito nacional, constituyen al Estado como sujeto de derecho internacional, tal como lo menciona el artículo 1. ${ }^{\circ}$ de la Convención Panamericana sobre los Derechos y Deberes de los Estados, firmada en Montevideo el 22 de diciembre de 1933, reconocida por el derecho internacional (OEA, 1933).

Sobre cada territorio, los Estados gozan del atributo de la soberanía; el Estado ejerce sus competencias en su espacio físico, también denominado ámbito territorial del Estado. En un histórico aporte, Kelsen refirió al territorio como el ámbito de validez de la norma jurídica.

El territorio estatal se define como aquel sobre el cual el Estado ejerce soberanía. Es preciso señalar los tres ámbitos espaciales que integran lo que se entiende por territorio nacional como contribución a las políticas de Estado:

El territorio terrestre está delimitado por las fronteras nacionales, determinadas por los tratados de límites que el Uruguay ha firmado con la Argentina y el Brasil, y comprende el suelo y el subsuelo. El subsuelo incluye las aguas subterráneas o acuíferos, como el Guaraní, sin perjuicio de que, al ser recursos compartidos y transnacionales, se pueda convenir sobre estos una gestión compartida, como sucede ya con el río Uruguay y el Río de la Plata.

El territorio marítimo incluye las aguas interiores y el mar territorial, que son los espacios donde el Estado ribereño ejerce soberanía absoluta, según la III Convención de las Naciones Unidas sobre Derecho del Mar, de 1982 (Convemar III) (ONU, 2005). Es importante precisar - porque a veces hay confusiones conceptuales - que las aguas interiores son las que están entre la costa y las líneas de base a partir de las cuales se cuentan las demás zonas marítimas. Parece contradictorio, pero aguas interiores son aquellas que se encuentran a partir de la costa. Se trata, por lo tanto, de aguas marítimas y no deben confundirse con las aguas internas, que son los lagos o ríos que están totalmente dentro del territorio terrestre y forman parte de él. El mar territorial lo constituyen las aguas y el subsuelo del Estado costero hasta un máximo de 12 millas contadas desde las líneas de base trazadas sobre la costa.

Finalmente, el espacio aéreo es el espacio atmosférico que se encuentra por encima del territorio terrestre de los Estados. La soberanía sobre él está claramente establecida desde la Convención de París de 1919. En 1994, con la entrada en vigor de la III Convención sobre Derecho del Mar, de 1982, quedó establecido que dicha soberanía sobre el espacio aéreo se aplica también por encima de las 12 millas del mar territorial, que, como se ha visto, se consideran territorio marítimo de los Estados. 
En su análisis de la dimensión territorial de las políticas públicas y transversalidad, Ricardo Gorosito Zuluaga (2009) entiende al territorio como la expresión de la relación compleja entre soporte físico (natural y artificial), actividades y organización humana. El territorio es una serie de procesos fuertemente caracterizados por su dimensión espacial y sistemática.

Surge del informe de la Comisión de Vivienda, Ordenamiento Territorial y Medio Ambiente de la Cámara de Senadores, en el marco del estudio de la Ley de Ordenamiento Territorial y Desarrollo Sostenible (Cámara de Senadores, Comisión de Vivienda, Ordenamiento Territorial y Medio Ambiente, 2007):

El territorio es el soporte, el lugar físico en que se desarrollan todas las actividades del hombre y de la sociedad; es indispensable para el desarrollo de la vida. Pero además es la sociedad instalada e interactuando en ese suelo; es un espacio de construcción social. Al hablar de territorio debemos pensar, entre otras cosas, en el suelo productivo, en las cuencas hidrológicas y en los sistemas de ciudades, en los recursos acuáticos, y en el sistema de transporte y comunicaciones, en los equipamientos e infraestructuras, y también en el desarrollo integrado, coordinado y sostenible de todas estas actividades y procesos. Pero fundamentalmente debemos pensar al suelo como soporte de nuestra producción agropecuaria, como sustento económico del país, como nuestro más importante recurso, que además es finito, no renovable e irreproducible.

En el concepto territorio están incluidas además las aguas territoriales, cuya riqueza trasciende el aspecto meramente productivo y a las que estamos obligados a preservar manteniendo la armonía del medio ambiente marino.

En el mismo sentido, la Comisión de Vivienda, Territorio y Medio Ambiente de la Cámara de Representantes (Uruguay. Cámara de Senadores, Comisión de Vivienda y Ordenamiento Territorial, 2007) presentaba el territorio como:

[...] aquel espacio geográfico y por tanto asociado a un límite administrativo establecido por una comunidad y que, a efectos del ordenamiento para su uso y con la finalidad de su desarrollo, el territorio es algo más que un escenario, es el espacio físico sostén de la vida, un soporte para la actividad humana. Además es el patrimonio más importante que tiene una sociedad, una comunidad. Hay una relación biunívoca entre una sociedad y su territorio.

Según la Carta europea de ordenamiento territorial, de 1983, el ordenamiento ('ordenación') del territorio, expresión espacial de las políticas económicas, social, cultura y ecológica de toda sociedad: 
Es a la vez una disciplina científica, una técnica administrativa y una política concebida como un enfoque interdisciplinario y global cuyo objetivo es el desarrollo equilibrado de las regiones y la organización física del espacio, según su principio rector.

[...] La realización de los objetivos del ordenamiento del territorio es esencialmente una tarea política.

[...]

Garantiza la coordinación entre los diferentes sectores

Este esfuerzo de síntesis debe involucrar esencialmente la distribución de la población, de las actividades económica, del hábitat, de los equipamientos colectivos y de las fuentes de energía, los transportes, el abastecimiento de agua y el saneamiento de las aguas cloacales, la eliminación de los ruidos y de los residuos, la protección del ambiente, de las riquezas y recursos naturales, históricos y culturales. (Consejo de Europa, 1983)

El Dr. Carlos Delpiazzo (2006), en un interesante trabajo titulado El ordenamiento territorial como cometido esencial del Estado, destaca la actividad de organizar jurídicamente el territorio. Expresa desde un enfoque general:

El ordenamiento territorial como cometido estatal ha adquirido en los últimos años una importancia teórica y práctica de envergadura, aun cuando se trata de un tema clásico vinculado a la planificación socioeconómica nacional que nuestra doctrina tradicional ha encartado entre los cometidos esenciales a través de aspectos tales como la vialidad, la conservación de bienes estatales y la ejecución de obras públicas.

Más específicamente, se ha dicho que la ordenación del territorio se corresponde con las grandes decisiones que los poderes públicos adoptan sobre el espacio, decisiones que deben ser acordadas y ejecutadas de acuerdo con objetivos predeterminados, tales como el logro de un desarrollo socioeconómico equilibrado de las diversas regiones del país, la mejora de la calidad de vida de los habitantes, la gestión responsable de los recursos naturales, la protección del medio ambiente y la utilización racional del suelo.

Desde tal perspectiva, es evidente que el ordenamiento territorial es más amplio que el urbanismo, que también supone una función ordenadora, ya que mientras el primero se relaciona con la adopción de decisiones sobre los destinos del suelo en aras de la consecución de un equilibrio territorial así como de la coordinación y racionalización de actividades, el segundo supone una función ordenadora del suelo y de la edificación de las ciudades en sentido estricto. 
Si bien ambos tienen en común la delimitación de los diversos usos a que puede destinarse el espacio físico territorial, la ordenación territorial lo hace desde una perspectiva integral, en tanto que el urbanismo lo hace en atención al ámbito espacial de un núcleo poblacional, que es la ciudad. Asimismo, el ordenamiento territorial es conceptualmente separable de la protección del medio ambiente, a la que muchas veces se lo filia como instrumento de aquella, lo cual no implica desconocer las interrelaciones existentes entre ambos cometidos.

\section{Ámbitos departamentales.}

\section{Antecedentes de actuación: Ley de Centros Poblados, 1946}

La Ley de Centros Poblados (10.723, de 1946) autoriza a los gobiernos departamentales a subdividir predios rurales con destino a la creación de centros poblados, así como a aprobar el trazado y la apertura de calles, caminos o sendas que impliquen amanzanamientos o la formación de un centro poblado.

\section{Departamento de Montevideo, 1947}

En 1947 la Intendencia Municipal de Montevideo ajustó sus reglamentaciones y procedimientos administrativos para encuadrarlos dentro de los preceptos de la Ley de Centros Poblados. Fue el único gobierno departamental que procede en ese sentido.

Ese hecho provocó un desplazamiento de los negocios de fraccionamiento urbano a los departamentos del interior, en especial a los limítrofes de Montevideo, en los cuales las autoridades municipales admitían divisiones de tierras con destino a centros poblados sin que se cumplieran con todo rigor las prescripciones de la ley.

Así nacieron las extensiones conocidas como las villas, en torno a la ruta 1 , en el departamento de San José, y a las rutas 5, 7 y 8, en el departamento de Canelones. Estos fraccionamientos se hicieron desconociendo las normas y los principios de la planificación urbana y transgrediendo muchas de las normas de la Ley de Centros Poblados (Álvarez Lenzi, 1986, citado por Urruzola, 2009).

\section{Departamento de Maldonado, 2006}

En 2006 - dos años antes de promulgarse la Ley de Ordenamiento Territorial y Desarrollo Sostenible - el departamento de Maldonado innovó y constituyó una instancia trascendente en su proceso histórico y social que forma parte de los antecedentes del ordenamiento de su territorio. 
Este departamento, ${ }^{1}$ en permanente desarrollo desde comienzo del siglo $\mathrm{xx}$, presenta notorias asimetrías, particularmente entre la zona costera y el interior rural. A lo largo del tiempo sigue recibiendo impulsos desarrollistas muy intensos en algunas zonas y no tanto en otras, lo que genera una mezcla de paisajes y realidades sociales.

Los diversos actores de la sociedad, su sector público y privado, entidades empresariales, gremiales, residentes permanentes y veraneantes, conjuntamente con la administración departamental y un equipo técnico de la Universidad de la República, llevaron adelante un proceso de planificación abierta y flexible para la ordenación del territorio departamental. Recogieron preocupaciones, inquietudes sobre la situación actual y visiones de futuro, y llegaron a propuestas de consenso.

Como testimonio de los acuerdos logrados en esta experiencia innovadora, se editaron los Cuadernos Territoriales. ${ }^{2}$ Estos incluyen en una relatoría del proceso, con antecedentes y un diagnóstico ilustrado desde distintas dimensiones (físico-espacial, ambiental, socioeconómica y político-jurídico-institucional), la visión de futuro y la agenda de propuestas consensuada, lo que la convierte en un recurso fundamental para la ciudadanía a la hora de reivindicar su derecho a incidir sobre los asuntos territoriales que le competen.

Se constata una concertación público-social y privada de acciones de ordenamiento para cada una de las escalas territoriales consideradas: la escala departamental, ${ }^{3}$ la escala microrregional ${ }^{4}$ y la escala urbana. ${ }^{5}$

La conquista y la colonización del actual territorio de departamental comenzó dos siglos y medio después del descubrimiento de estas tierras por los europeos. La Villa de San Fernando de Maldonado fundada por José Joaquín de Viana en 1755. Desde 1874 hasta la extensión del trazado ferroviario, que finalizó en 1929, se originaron varios poblados en el departamento. Al principio estaban habitados por vecinos de las ciudades de Maldonado, San Carlos y Pan de Azúcar, pero luego se ampliaron luego con población extrarregional y generaron enclaves de resonancia internacional.

2 Una colección de nueve tomos, uno de los cuales trata la escala departamental y ocho que abordan las escalas microrregionales. Disponible en: http://www.fadu.edu.uy/itu/publicaciones/

3 Es la discusión del rol que desempeña el departamento de Maldonado — que integra la región que se ha dado en llamar Costa Sur del Uruguay - en relación con el juego de competencias y complementariedades entre los territorios mencionados.

4 Estudia las relaciones de las localidades urbanas de la microrregión con sus entornos rurales naturales, productivos o turísticos. La determinación de los límites de dichas microrregiones fue uno de los conflictos planteados, en el que finalmente primó el criterio de la gestión y la administración que se ha venido implementando históricamente en el departamento.

5 Maldonado - Punta del Este - San Carlos, segunda aglomeración de la franja costera en importancia de la región metropolitana del sur del país después de la de Montevideo, es un territorio de alta complejidad funcional, socioeconómica y política, hecho por el cual gravita decisivamente en el conjunto del departamento. Con cerca del $80 \%$ de la población departamental, constituye un polo regional, cuya calidad y diversidad de equipamiento ha venido mejorando en forma sostenida, y recibe la mayor parte del flujo turístico del país. Estas particulares condiciones se agregan a las cualidades paisajísticas y ambientales que reúnen Maldonado, Punta del Este y otros balnearios y parajes del departamento. 
Se propone una nueva mirada de los variados paisajes que integran la región del departamento: el paisaje de serranía, su fauna y vegetación autóctonas, el paisaje asociado al sistema hídrico (mar, lagunas, humedales, cursos de agua), parajes rurales con su infraestructura de referencia (escuelas, almacenes, viviendas singulares), paisajes asociados a la producción agrícola (vid, olivo) y ganadera, así como paisajes asociados a la explotación minera y a la infraestructura ferrocarrilera.

Como corolario del proceso descrito, resulta interesante detallar una propuesta de los participantes que manifiesta el interés por valorizar el singular entorno rural del departamento, destacando su capital natural y construido frente a las incipientes sustituciones de usos productivos tradicionales.

Surgió así el proyecto Arco del Sol, iniciativa basada en los recursos naturales, culturales y su patrimonio, en el sentido más amplio. ${ }^{6}$

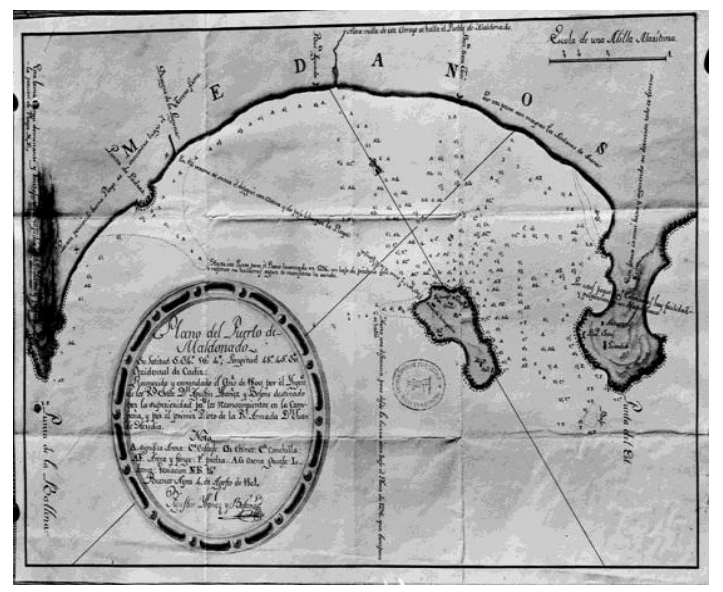

Figura 1. Plano del Puerto de Maldonado, 1801. Centro de Fotografía de Montevideo (CDF)

Es una propuesta de turismo alternativo estructurada sobre un recorrido de interés paisajísticocultural por el área rural del departamento, que abarca 200 kilómetros de extensión. El objetivo es poner en valor el patrimonio rural y redescubrir el norte del departamento, lo que sumado a las cualidades paisajísticas y ambientales le permiten constituirse en una opción significativa como destino turístico nacional e internacional. 


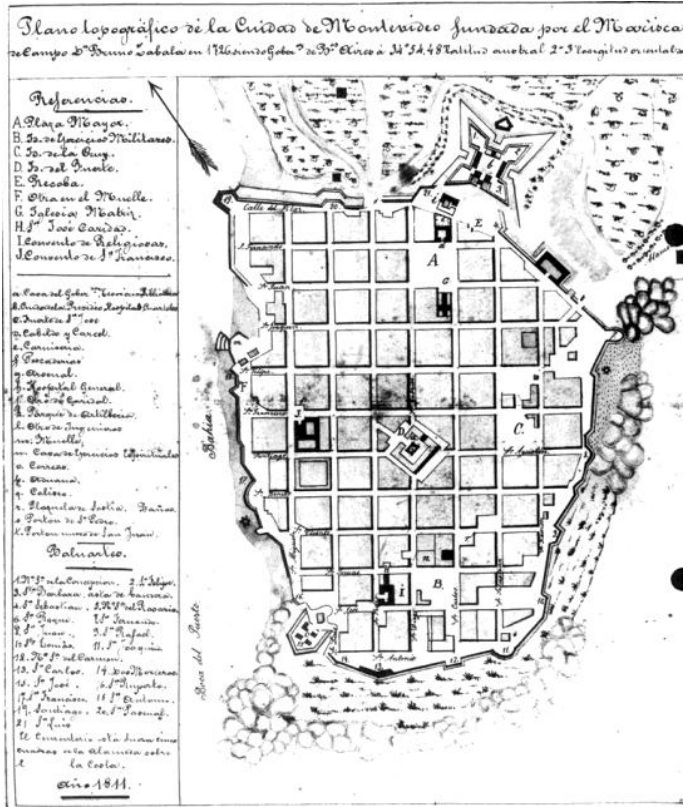

Figura 2. Plano de la ciudad de Montevideo, 1811. Centro de Fotografía de Montevideo (CDF)

\section{Antecedentes legislativos inmediatos}

\section{Ley de Ordenamiento Territorial y Desarrollo Sostenible (18.308)}

El Ordenamiento Territorial con distintos nombres a través de la historia ha tenido una referencia urbana en contraposición a lo rural, con el paso del tiempo fue evolucionando hasta llegar a nuestros días con el surgimiento de la disciplina del Ordenamiento Territorial.

Desde la década de los cuarenta hasta hoy nuestro País dispone de una legislación que forma parte de los antecedentes de la primera Ley de Ordenamiento Territorial y Desarrollo Sustentable del Uruguay promulgada en el año 2008 (Ley No 18.308)

Al primer Anteproyecto encarado por la Dirección Nacional de Ordenamiento Territorial (DINOT) del Ministerio de Vivienda y Ordenamiento Territorial y Medio Ambiente en adelante MVOTMA, se lo llamo (Anteproyecto de) Ley de Ordenamiento y Desarrollo Territorial según palabras de Arq. Manuel Romay, entonces Ministro de Vivienda.

El mismo nombre de Proyecto de Ley de Ordenamiento y Desarrollo Territorial lució el Anteproyecto elevado por el MVOTMA al Poder Ejecutivo en la segunda adminis- 
tración del Dr. Julio M. Sanguinetti y que en definitiva no se remitiera al Parlamento (Gorosito Zuluaga y Ligrone, 2009).

Como también lo manifiestan estos autores, el proceso de gestación de la norma vigente LOTDS fue resumido por las autoridades ministeriales de la época en su comparecencia a la Comisión de Vivienda y Ordenamiento Territorial del Senado el 27 de setiembre de 2006 (Uruguay. Cámara de Senadores, Comisión de Vivienda y Ordenamiento Territorial, 2006). En esa fecha se dio inicio al tratamiento parlamentario del recién ingresado Proyecto de Ley de Ordenamiento y Desarrollo Territorial Sostenible. Al respecto el señor ministro Mariano Arana manifestó:

Comenzaría por afirmar que este proyecto de Ley de Ordenamiento y Desarrollo Territorial Sostenible es, de algún modo, un producto acumulativo de conocimientos - tanto de origen nacional como internacional - en la materia en la que se pretende legislar.

En primer lugar, quiero señalar que en nuestro país existen antecedentes legislativos al respecto. Particularmente, me refiero al proyecto de ley que en la Legislatura anterior elevó el Poder Ejecutivo al Poder Legislativo.

En segundo término cabe destacar que dicha iniciativa fue considerada en la Comisión de Vivienda y Ordenamiento Territorial, lo que también sirvió de antecedente - mediante la versión taquigráfica que pudo consultarse - para la estructuración final del proyecto articulado que ahora los señores Senadores poseen en una carpeta.

En tercer lugar, también hay que tener en cuenta la iniciativa que presentó la Dirección Nacional de Ordenamiento Territorial sobre el final de todo este proceso de investigación y análisis. Se trata de un documento que bajo el título, "Ocho ideas claves para la ley de ordenamiento territorial", fue aprobado por la Comisión Técnica Asesora de ordenamiento territorial a principios de junio de 2004. Asimismo existieron propuestas de carácter legislativo de distintas Intendencias del país.

En cuarto término, se pueden subrayar los aportes que surgieron de algunos ámbitos académicos, en particular los de la Cátedra de Arquitectura Legal de la Facultad de Arquitectura de nuestra Universidad de la República....”

A esta cantidad de elementos también podríamos sumar, como antecedente, un quinto aspecto que refiere a las experiencias europeas en materia de legislación, particularmente concretadas en el asesoramiento que hemos recibido de la Junta de Andalucía a partir del Protocolo suscrito en marzo de 2006 con la Consejería de Obras Públicas y Transportes de dicha Junta. Tengamos en cuenta que la Junta de Andalucía también asesoró a la Intendencia Municipal de Montevideo, a raíz de lo cual se pudo concretar un Plan de Ordenamiento Territorial del departa- 
mento, logrando una amplia votación favorable de la Junta Departamental de Montevideo.

El 18 de junio de 2008 fue promulgada la Ley de Ordenamiento Territorial y Desarrollo Sostenible (LOTDS), con el número 18.308, y el 30 de ese mes se publicó en el Diario Oficial.

Ricardo Gorosito Zuluaga (2009) aclara que la LOTDS no es un producto importado de España ni copiado de la Ley de Suelo española de 1956 y sus evoluciones. Considera que es el resultado de al menos diez fuentes históricas de inspiración doctrinal y jurídica:

- el urbanismo en general;

- la legislación uruguaya de centros poblados y de fraccionamiento de la propiedad;

- la legislación uruguaya en materia de régimen de bienes inmuebles y de la propiedad inmobiliaria;

- el ordenamiento territorial francés;

- el desarrollo local;

- el desarrollo regional;

- la ordenación urbana española;

- el ambientalismo;

- los instrumentos de desarrollo y ordenamiento territorial uruguayos;

- la planificación.

Su hechura, dice Gorosito Zuluaga (2009), es uruguaya.

\section{Segunda parte}

\section{Marco jurídico del ordenamiento territorial en Uruguay}

Hablar de marcos y de instrumentos normativos jurídicos del planeamiento y de la legislación urbana requiere establecer un puente entre la comprensión que se tenga de la vida social y física de un territorio y los instrumentos de comprensión de las decisiones sociales y las normas que las regulan.

Patricio Rodé (1994) 


\section{Definición de la materia y su objeto}

De la planificación territorial se ocupó el Programa de Agenda $21^{7}$ de las Naciones Unidas en la Cumbre de Río de Janeiro, en 1992. Allí se expresó que, si en el futuro se quiere satisfacer las necesidades humanas de manera sostenible, es esencial encaminarse hacia un uso más eficaz y eficiente de la tierra y sus recursos naturales, mediante un enfoque integrado de la planificación y la gestión del medio físico y el uso de la tierra (ONU, s.f.).

Uruguay dispone de una legislación de ordenamiento territorial que, con distintos nombres a través de la historia, hoy forma parte de los antecedentes de la LOTDS, sancionada el 18 de junio de 2008.

Varias leyes aprobadas, algunas en el siglo XIX y otras durante el siglo XX, regulan sobre lo que hoy es la materia del ordenamiento territorial. Con la LOTDS se establece una base normativa que dispone competencias y atribuye roles a los distintos niveles gubernamentales y obliga a determinadas conductas tanto a las propias unidades estatales como a los particulares.

La ley consta de 83 artículos ordenados en ocho títulos que definen:

- Disposiciones generales de ordenamiento territorial, los fines y la naturaleza del ordenamiento territorial.

- Instrumentos de planificación territorial. Los derechos y deberes territoriales de las personas y de la propiedad inmueble, los instrumentos de la planificación en sus diversas escalas.

- La planificación para el desarrollo sostenible, los criterios generales que ordenan los usos de suelo y controlan su sostenibilidad y los mecanismos de participación social y de coordinación institucional.

- La actuación y el control en el marco del ordenamiento territorial.

- La participación social en el ordenamiento territorial.

- La coordinación interinstitucional para el ordenamiento territorial.

- Disposiciones especiales.

La LOTDS procede a regular esta materia abordando el objeto que dispone en su artículo $1 .^{\circ}$ :

7 Programa 21 se gestó en la Conferencia Mundial sobre el Medio Ambiente y Desarrollo Sostenible organizada por Naciones Unidas en Río de Janeiro (Brasil) en 1992, también conocida como Cumbre de la Tierra. Se trataba de apoyar iniciativas que construyeran un modelo de desarrollo sostenible para el siglo XXI, de ahí su nombre. Fue suscrita por 172 países miembros de las Naciones Unidas. Estos se comprometen a aplicar en el ámbito local políticas ambientales, económicas y sociales encaminadas a lograr un desarrollo sostenible. Es, en definitiva, un compromiso hacia la mejora del medio ambiente $y$, por ende, de la calidad de vida de los habitantes de una comunidad, municipio o región. 
- La definición de las competencias y los instrumentos de planificación, participación y actuación en la materia.

- La orientación del proceso de ordenamiento del territorio hacia la consecución de objetivos de interés nacional y general.

- El diseño de los instrumentos de ejecución de los planes y de actuación territorial.

En su artículo $3 .^{\circ}$ la LOTDS incorpora la propia definición de la materia objeto de regulación. La ley entiende el ordenamiento territorial como:

El conjunto de acciones transversales del Estado y de la sociedad que tienen por finalidad mantener y mejorar la calidad de vida de la población, la integración social en el territorio y el uso y aprovechamiento ambientalmente sustentable y democrático de los recursos naturales y culturales.

Procede a regular los cuatros aspectos que integran la materia de ordenamiento territorial: la actividad de planificación territorial, la actividad de gestión territorial, la actividad de control y disciplina territorial, y por último establece el régimen jurídico de la propiedad del suelo vinculada a los fines del ordenamiento territorial. Estos aspectos están definidos en los apartados $a$ a $i$ del mismo artículo:

- La definición de estrategias de desarrollo sostenible en el uso del territorio en función de objetivos sociales y económicos a través de la planificación.

- El establecimiento de criterios para la localización de las actividades económicas y sociales.

- La identificación y la definición de áreas bajo régimen de especial protección por su interés ecológico, patrimonial, paisajístico, cultural y de conservación del medio ambiente y los recursos naturales.

- La identificación de zonas de riesgo por la existencia de fenómenos naturales o de instalaciones peligrosas para asentamientos humanos vulnerables.

- La definición de equipamiento e infraestructuras y de estrategias de consolidación del sistema de asentamientos humanos.

- La previsión del territorio a los fines y usos considerados en los planes.

- El diseño y la adopción de instrumentos y procedimientos de gestión que promuevan la planificación del territorio.

- La elaboración e instrumentación de programas, proyectos y actuaciones con incidencia territorial. 
- La promoción de estudios para la identificación y el análisis de los procesos políticos, sociales y económicos de los que derivan las modalidades de ocupación y ordenamiento del territorio.

Como ley marco, la LOTDS remite al Poder Ejecutivo y a los gobiernos departamentales la labor de desarrollo de la norma.

\section{Ley de Ordenamiento Territorial y Desarrollo Sustentable. Principios rectores}

Establece la LOTDS en su artículo $5 .^{\circ}$ los principios rectores que caracterizan la política del ordenamiento territorial.

El primero es el principio rector de la planificación y de la sustentabilidad. La planificación se configura como una herramienta válida para la ordenación del territorio y se considera legítima aquella que sea ambientalmente sostenible ${ }^{8} \mathrm{y}$ garantice la equidad social y la cohesión territorial.

Este principio se relaciona directamente con otros que la ley señala en el artículo 5. (incisos $h, i, j$ ), respecto a la conciliación del desarrollo económico, la sustentabilidad ambiental y la equidad social, con objetivos de desarrollo integral, sostenible y cohesionado del territorio, que deberán compatibilizarse con una equilibrada distribución espacial de los usos y actividades y el máximo aprovechamiento de la infraestructura y los servicios existentes.

Ese desarrollo de los objetivos de contenido social y económico deberá ser compatible con la conservación de los recursos naturales y el patrimonio cultural y con la protección de los espacios de interés productivo rural.

La creación de condiciones para el acceso igualitario de todos los habitantes a su calidad de vida que garanticen la accesibilidad a equipamientos y servicios públicos necesarios, así como el acceso equitativo a un hábitat adecuado, es otro de los principios señalados.

Se incluye asimismo la tutela y valorización del patrimonio cultural, constituido por el conjunto de bienes en el territorio a los que se atribuyen valores de interés 
ambiental, científico, educativo, histórico, arqueológico, arquitectónico o turístico, referidos al medio natural y a la diversidad biológica, unidades de paisaje, conjuntos urbanos y monumentos.

El principio rector de participación ciudadana en las decisiones territoriales se interpreta como garantía de la participación de los ciudadanos en los procesos de seguimiento, evaluación y revisión de los instrumentos de ordenación y de control.

Se desprende de este principio el reconocimiento legal del derecho colectivo a la ciudad, vinculado directamente con el título II de la ley, que en su artículo 6 trata de los derechos y deberes territoriales de las personas:

- El derecho de toda persona a que los poderes públicos establezcan un ordenamiento territorial adecuado a los intereses generales, en el marco de los derechos y garantías establecidos en la Constitución de la República.

- El derecho de toda persona a participar en los procesos de elaboración de los instrumentos de ordenamiento territorial.

- La posibilidad de que toda persona demande ante la sede judicial correspondiente la observancia de la legislación territorial y de los instrumentos de ordenamientos en todos los acuerdos, actos y resoluciones que adopten las instituciones públicas.

- El derecho de toda persona al acceso de la información sobre el territorio que posean las instituciones públicas.

- El derecho de toda persona al uso común y general de las redes viales.

- El principio rector de la distribución equitativa de cargas y beneficios del proceso urbanizador entre los actores públicos y privados y la recuperación de valores inmobiliarios generados por el ordenamiento territorial.

De aquí surge la coordinación entre el sector público y el privado en el proceso de urbanización.

Otro principio rector de la LOTDS es la descentralización. En el inciso $c$ del artículo 5. ${ }^{\circ}$, la ley apuesta a la «descentralización de la actividad de ordenamiento territorial y a la promoción del desarrollo local y regional, poniendo en valor los recursos naturales, construidos y sociales presentes en el territorio».

Para asegurar el cumplimiento de sus objetivos de interés general, la LOTDS reconoce que la actividad de ordenamiento territorial es una función pública cuyo ejercicio está a cargo de los poderes públicos según sus competencias y de acuerdo a nuestra Carta Magna, y se materializa «[...] en un conjunto de directrices, planes, programas y actuaciones de todas las instituciones del Estado competentes, a fin de organizar el uso del territorio» (artículos $2 .^{\circ}$ y $3 .^{\circ}$, ley 18.308) 
Se impone el precepto constitucional del artículo 50, inciso $3 .^{\circ}, 9$ según el cual el Estado impulsará la descentralización, dentro de las materias que le son propias y las oportunas que puedan favorecerla.

En este punto es necesario señalar diferencias para no confundir una ley de ordenación territorial con una ley de descentralización. No son sinónimos. La descentralización puede entenderse como el ejercicio y la distribución de los recursos en el espacio geográfico.

Si bien en el contexto de la ley es una consecuencia deseable, la descentralización responde a un mandato constitucional.

La LOTDS describe los asuntos urbanos y territoriales como de especial interés departamental.

\section{Tercera parte}

\section{La propiedad y el territorio}

"Hay que encontrar un justo equilibrio entre el respeto de los derechos individuales y el cumplimiento de los cometidos estatales en la materia del ordenamiento territorial. El derecho da los mecanismos para solucionarlo".

(Carlos Castro Casas, 2012)

La LOTDS, particularmente en el régimen de la propiedad territorial, ha sido objeto de opiniones encontradas. Unas manifestaban reservas en lo referido a modificaciones que la ley estaría haciendo al régimen de la propiedad privada, y sobre esa base sostenían su inconstitucionalidad, mientras que otras no veían en el régimen de la propiedad establecido por la ley nada que afectara el derecho de propiedad consagrado por la Constitución de la República, los principios generales de derecho que regulan la propiedad territorial, el Código Civil y la Ley de Centros Poblados, sus modificaciones y normas sobre la materia.

\section{El derecho de propiedad}

En nuestra legislación el derecho de propiedad tiene su base en el derecho romano y se señala como contenido de la propiedad el ius utendi, que comprende la facultad

9 Artículo 50, inciso 3.: «Asimismo, el Estado impulsará políticas de descentralización, de modo de promover el desarrollo regional y el bienestar general» (Constitución de la República Oriental del Uruguay, 1967). 
de utilizar la cosa tanto para el destino que tenía cuando se la recibió como para cualquier otro destino lícito que se resuelva atribuirle posteriormente, como también la facultad de conceder el derecho o parte de él a terceros, bajo la forma de diversos derechos personales.

El ius fruendi comprende la facultad de percibir los frutos, tanto los de percepción periódica como aquellos que el Código Civil (ley 16.603, 1994) denomina naturales, industriales o civiles que la cosa produzca o pueda producir en cualquiera de sus destinos lícitos, y también los denominados productos, como los beneficios de percepción no periódica que de la cosa se puedan obtener lícitamente.

El ius abutendi es el derecho a abusar de la cosa. En general se entiende como derecho de disposición, que comprende las facultades de enajenar la cosa afectada con derechos reales a favor de otros sujetos, entre los que se incluyen los derechos de goce, los de garantía y otros tipos de derechos reales que pueden constituirse.

La Constitución de la República consagra en su artículo 7:

Los habitantes de la República tienen derecho a ser protegidos en el goce de su vida, honor, libertad, seguridad, trabajo y propiedad.

Nadie puede ser privado de estos derechos sino conforme a las leyes que se establecieren por razones de interés general. (Semino, anot., 1997)

Por su parte, el artículo 32 dispone:

La propiedad es un derecho inviolable, pero sujeto a lo que dispongan las leyes que se establecieron por razones de interés general. Nadie podrá ser privado de su derecho de propiedad sino en los casos de necesidad o utilidad públicas establecidos por una ley y recibiendo siempre del Tesoro Nacional una justa y previa compensación. Cuando se declare la expropiación por causa de necesidad o utilidad públicas, se indemnizará a los propietarios por los daños y perjuicios que sufrieron en razón de la duración del procedimiento expropiatorio, se consume o no la expropiación; incluso los que deriven de las variaciones en el valor de la moneda. (Semino, anot., 1997)

Por otra parte, establece el artículo 487 del Código Civil (Cafaro y Carnelli, anot. 2007):

El derecho de gozar y disponer de una cosa comprende: 1) El derecho a todos los frutos que provienen de la cosa y a todo lo que se le una accesoriamente. 2) El de servirse de la cosa, no solo para los usos a que está generalmente destinada, sino para los otros que están en la voluntad del dueño. 3) El de cambiar la forma de la 
cosa mejorándola o empeorándola. 4) El de destruir enteramente la cosa, si le conviene o le parece. 5) El de impedir a los demás que se sirvan de ella y reivindicarla de cualquier poseedor. 6) El de enajenar la cosa en todo o en parte, concediendo a otros los derechos que buenamente quiera.

Y el artículo 486 del mismo código prevé:

El dominio [...] es el derecho de gozar y disponer de una cosa arbitrariamente, no siendo contra la Ley o contra derecho ajeno.

La Constitución de la República consagra que la propiedad es un derecho inviolable, y se desprende del Código Civil, en sus artículos 486 y 488, que la propiedad es un derecho a usar y gozar de la cosa arbitrariamente. Ambas normas refieren a que el derecho de propiedad está limitado por razones de interés general contra el derecho ajeno.

La doctrina juspublicista ha entendido que el ordenamiento constitucional establece un régimen de amplia protección del derecho de propiedad, pero de ninguna manera irrestricto e ilimitado.

La amplitud de concepto de propiedad constitucionalmente protegido en el Uruguay deriva de que equivale a todos los derechos de naturaleza patrimonial (Gorosito Zuluaga y Ligrone, 2009).

Desde el punto de vista doctrinario, el derecho de propiedad es un derecho patrimonial de naturaleza real, que tiene como características:

a. La inmediatez: El propietario tiene una relación inmediata con la cosa, goza directamente de ella.

b. La independencia: No se encuentra subordinado, por lo que el propietario de la cosa puede disponer de ella arbitrariamente, excepto contra la ley o contra el derecho ajeno.

\section{Cuarta parte}

\section{Principios de seguridad y certeza jurídica}

Dos valores sin los cuales no puede vivir la sociedad de un Estado de Derecho, el principio de la seguridad jurídica y el principio de certeza del Derecho y su previsibilidad como ordenador de las conductas, sin los cuales sería difícil hablar de una sociedad libre.

(Eduardo García de Enterría) 
Los principios de seguridad y certeza jurídica conforman otro foco de esta temática. El término seguridad proviene del latín securitas, el cual deriva del adjetivo securus, que se refiere a lo cierto, lo confiable, lo indemne, lo conocido, lo indubitable, lo responsable.

Según el Diccionario de la lengua española, de la Real Academia Española (2001), seguridad jurídica es, en única acepción, la «Cualidad del ordenamiento jurídico que implica la certeza de sus normas y, consiguientemente, la previsibilidad de su aplicación».

La seguridad jurídica proporciona certeza a todo el derecho o sistema jurídico, hace cierto al ordenamiento (en el sentido gramatical propio del término), y lo transforma, en términos del mismo diccionario, en algo cognoscible (conocible) de forma segura y clara, en algo a lo que la mente puede adherirse firmemente sin temor a errar. En otras palabras, lo convierte en algo indubitado, previsible, que todos los ciudadanos pueden conocer y tener por verdadero. Este es el sentido propio del concepto de seguridad jurídica.

El derecho tiene que ser cierto, seguro, predecible, inequívoco, de tal modo que podamos ajustar nuestra conducta a sus dictados sin temor a equivocarnos, a obrar mal o a recibir una sanción. Si las normas o instituciones jurídicas no fueran conocidas, seguras o indubitadas, si permanecieran ocultas o secretas, si fueran dudosas o inciertas, sería imposible la vida común y, por ende, la justicia, el progreso y el propio desarrollo del tejido social.

El Estado, como máximo exponente del poder público y primer regulador de las relaciones en sociedad, no solo establece (o debe establecer) las disposiciones legales que es necesario observar, sino que, en un sentido más amplio, tiene la obligación de crear un ámbito general de seguridad jurídica al ejercer el poder político, jurídico y legislativo.

En resumen, la seguridad jurídica es la certeza del derecho que tiene el individuo, de modo que su situación jurídica no será modificada más que por procedimientos regulares y conductos legales establecidos, previa y debidamente publicados.

\section{¿En qué reside la seguridad jurídica?}

\section{¿Qué convierte a una norma o institución jurídica en segura, es decir, en clara, inequívoca y predecible?}

Para Linares Quintana (1956), seguridad jurídica es el conjunto de las condiciones que posibilitan la inviolabilidad del ser humano; es el ambiente sin cuya existencia resulta imposible la manifestación y el cabal desarrollo del individuo, sin el cual no pue- 
de haber libertad. Solamente la seguridad avienta del alma humana el temor, o sea, el recelo de un daño futuro, provenga este de otros individuos o del Estado. La seguridad jurídica equivale así, según este autor, a la libertad del hombre frente al temor. Una condición esencial para ello es que las circunstancias y los factores que puedan influir de manera eficaz en la posibilidad de conformar y ejecutar los proyectos personales, en especial las intervenciones del Estado a tales efectos, puedan ser calculadas del modo más fiable posible.

Para Sanz Moreno, el conocimiento cierto de las normas y los actos jurídicos depende de un doble factor: la publicidad y la existencia de un procedimiento de elaboración establecido. Se puede considerar que los elementos básicos del principio de seguridad jurídica son tres: a) la publicidad de las normas y los actos jurídicos; b) la existencia de una forma prefijada para ellos; c) la estabilidad de las situaciones y posiciones jurídicas consolidadas. De la conjunción de esos tres factores resulta esa cualidad del ordenamiento que hace que los operadores jurídicos y los ciudadanos sepan a qué atenerse, lo cual supone, por un lado, un conocimiento cierto de las leyes vigentes $y$, por otro, cierta estabilidad de las normas y de las situaciones que en ella se definen.

\section{Conclusiones}

Uruguay dispone de una legislación de ordenamiento territorial que, con distintos nombres a través de la historia, hoy forma parte de los antecedentes de la Ley de Ordenamiento Territorial y Desarrollo Sostenible, del 18 de junio de 2008.

Varias leyes aprobadas, algunas en el siglo XIX y otras durante el siglo XX, contienen regulaciones sobre lo que hoy es la materia del ordenamiento territorial. Esta ley establece una base normativa que fija competencias y atribuye roles a los distintos niveles gubernamentales y obliga a conductas tanto a las propias unidades estatales como a los particulares.

Es posible identificar un consenso en asumir el ordenamiento territorial como política pública que implica un proceso planificado del territorio, donde lo técnico, lo político y lo administrativo desempeñan papeles específicos.

El ordenamiento territorial forma parte de los contenidos de la función administrativa del Estado e implica el abordaje de un cometido estatal asignado por una norma jurídica.

El objetivo es organizar, armonizar y administrar el uso y la ocupación del territorio, a fin de colaborar al desarrollo y sumar espacios que brinden calidad de vida, en busca de la sustentabilidad del equilibrio intra e interregional y el uso racional y justo de los recursos ambientales. 
En el marco de los ocho títulos que definen la LOTDS, este trabajo de investigación se ha centrado en analizar las disposiciones del derecho de propiedad, y posteriormente atenderá al derecho de superficie, la preferencia y el instituto de prescripción adquisitiva.

Se han presentado de forma cronológica los antecedentes históricos de la ley, la legislación vigente durante el siglo xx en el Uruguay, sus antecedentes inmediatos y su marco jurídico y conceptual, que surgen de los resultados de fuentes históricas de inspiración doctrinal y jurídica.

Los objetivos de la disciplina propician cambios positivos en la organización del espacio, al tiempo que atienden problemas territoriales emanados de conflictos de intereses que la acción de diversos agentes tiene sobre el espacio.

Los procedimientos que describe la ley comprenden el derecho a la participación y a su legitimación activa, el reconocimiento de la acción pública en defensa del ordenamiento territorial, que legitima al ciudadano para exigir ante la sede judicial el respeto de la legislación territorial y el contenido de los planes, actos y resoluciones que adopten las instituciones públicas.

Se reconoce como derecho público el acceso a la información territorial y el derecho colectivo al uso general de los bienes públicos.

El principio de descentralización se adopta como criterio de distribución de competencias en materia de ordenación territorial, reconociendo primeramente las competencias concurrentes de los órganos estatales y la coordinación entre las diversas instancias públicas que inciden en el territorio.

El territorio como tal es un bien de enorme relevancia para el desarrollo de una nación. Por eso incorporarlo en un plan de ordenamiento territorial se torna esencial.

El derecho de propiedad es entendido como derecho fundamental de los habitantes de la República, junto con otros derechos y garantías. En ese derecho fundamental, las potestades reconocidas a los individuos como esenciales - es decir, de las que no puede ser privado- están consagradas en los artículos 7 y 32 de la Constitución de la República. En este sentido se aproxima a lo que el legislador consideró para fundamentar el interés general en la norma.

La limitación al derecho de propiedad parecería insertarse en un concepto de propiedad en su función social, aunque el régimen uruguayo se construyó en armonía del interés individual y del interés general.

La Constitución mantiene las garantías del derecho inviolable de la propiedad, atendiendo al mismo tiempo a las competencias legislativas, con el objetivo de adaptarlas a las necesidades de la vida actual, pero lo sujeta a lo que dispongan las leyes que se establezcan por razones de interés general.

Durante el curso de esta investigación, en distintas entrevistas recogí opiniones que consideraron el fundamento de esta LOTDS como herramienta para solucionar la 
realidad de los asentamientos irregulares instalados en el territorio. Al respecto entiendo que la ley es más profunda y amplia en su materia. De todas formas, frente a tal situación y sin eludir la respuesta, he de señalar que las estructuras de las familias que ocupan los asentamientos irregulares y las características de su hábitat necesitan una forma jurídica adecuada, con certeza jurídica para aplicar en su regularización y en el marco del régimen de la propiedad, lo cual no impediría que las normas establecidas en la LOTDS en materia de función social se incorporaran a las áreas debidamente planificadas en cada localidad y de acuerdo a los requisitos que la ley y la Constitución establecen.

Para adoptar esa solución jurídica se deberá integrar el conocimiento interdisciplinario del derecho en todas sus áreas, acorde a la realidad, y el Estado deberá también intervenir cuando se desvirtúe el destino o el fin por el cual se orientó la norma, a fin de recuperar las viviendas amparadas y disponer de ellas.

Se deberá demostrar claramente que la ocupación es una situación que se configuró por situaciones complejas, donde existen estados de necesidad real que, como consecuencia, impactan en la salud, la educación y la seguridad, y que inciden en el comportamiento de las personas y en la calidad de vida comunitaria, las estructuras y el lugar habitacional de la comunidad, su emplazamiento en el territorio y el acceso a servicios fundamentales (agua, luz, caminaría transitable, transporte e instalación de instituciones esenciales de salud y educación).

Será trascendente valorar su importancia a la hora de tomar decisiones, adoptar políticas nacionales, regionales o locales que, como norma, responden al reconocimiento de un derecho humano esencial, de alcance individual y colectivo, y orientan el actuar diligente de las autoridades públicas nacionales y departamentales para su efectiva consecución.

Finalmente la síntesis indica que el derecho da los mecanismos para aportar soluciones a través del justo equilibrio en el marco del respeto de los derechos individuales y el cumplimiento de los cometidos estatales que la materia del ordenamiento territorial dispone.

Es indudable que, en la documentación de los derechos a que refieren los citados institutos, el escribano está llamado a cumplir un rol fundamental y trascendente en la aplicación del derecho en forma no contenciosa, mediante su labor de asesoramiento y su intervención mediadora si esta fuera requerida por las partes.

Si el orden jurídico es fórmula de convivencia social, el derecho debe hallar en él la posibilidad de un desenvolvimiento plenamente eficaz. Considero que tiene mucho que aportar a la ley en estudio y en particular a los institutos a los que refiere esta investigación, a efectos de lograr su próxima y necesaria reglamentación.

En los abordajes jurídicos de hoy y en aquellos que atienden a leyes con especial trascendencia y significación social, como es el caso de la ley en estudio, se hace nece- 
sario trabajar de forma inter, multi y transdisciplinaria. Ello implica sencillamente analizar, debatir, discutir y compartir las especialidades de todas las ramas del derecho involucradas en su gestión.

Sin duda, la tarea no es sencilla, porque no se puede perder de vista la realidad histórica, social y cultural que se pretende regular, y a la vez porque hay un sinnúmero de relaciones jurídicas implícitas capaces de generar varios derechos subjetivos e intereses legítimos, deberes y facultades que deben converger en la convivencia humana y en la integración armónica y responsable de la persona con su hábitat, que no solo tiene actualidad sino proyección para las generaciones futuras.

El finalidad es clara: obtener un resultado consensuado para alcanzar una unidad de pensamiento que permita el cumplimiento de los objetivos queridos por la regla de derecho.

El resultado de esta interacción dejará las puertas abiertas a nuestra sociedad para su desarrollo sostenible y para ratificar una vez más la importancia social del derecho, parte integrante de los fundamentos que garantizan con aliento sostenido las políticas de Estado, de manera de establecer grandes líneas directrices que orienten y hagan cada vez más digna y armónica la vida humana en el territorio del país.

Recomiendo especialmente la conformación de un grupo multidisciplinario para la debida coordinación de los instrumentos del derecho que sustentan y regulan situaciones en el marco de la ley, como, por ejemplo, aquellas que claramente se deberán reglamentar por cuanto refieren a limitaciones del ejercicio del derecho de propiedad provenientes de planes de ordenación y se consideren comprendidas en el concepto de interés general, u otras situaciones que pudiera delimitar el derecho de propiedad sobre el suelo cuyas disposiciones no quedan claras en esta ley.

La norma jurídica y sus disposiciones deberán fijar competencias, derechos y obligaciones con reglas claras, atendiendo también a las consultas de los actores sociales.

En síntesis, los procesos del ordenamiento territorial deben estar respaldados con sujeción a un cuerpo normativo que otorgue legalidad institucional.

Dicho grupo multidisciplinario debería integrar la visión de representantes del Poder Ejecutivo, del Ministerio de Vivienda, Ordenamiento Territorial y Medio Ambiente, del Congreso de Intendentes, de los gobiernos departamentales (legislativo y ejecutivo), y es de vital importancia que integre especialistas en las materias con mayores posibilidades de enriquecer las normas a dictarse: derecho constitucional, público, administrativo, civil, procesal, notarial, registral, ambiental y urbanístico. La recomendación se fundamenta en que los programas, acciones y funciones de la ordenación del territorio no pueden ser desarrollados de forma disociada o contrapuesta al derecho, sino que deben sujetarse a un cuerpo normativo que otorgue legalidad institucional. 
En mi opinión, la Ley de Ordenamiento Territorial y Desarrollo Sostenible, primera en su género en Uruguay, es ejemplo de una legislación en movimiento. Este trabajo de investigación deja las primeras reflexiones para su continuidad y abre la puerta a nuevos aportes que conduzcan a su perfeccionamiento y consolidación.

\section{Bibliografía}

Consejo de EuRopa (1983). Carta europea de ordenación del territorio. Recuperado de: https://alojamientos.uva.es/guia_docente/uploads/2013/474/46059/1/Docum ento37.pdf.

Constitución de la República Oriental del Uruguay (1967). Asamblea General, Montevideo, Uruguay, 24 de agosto de 1966.

DELPIAZZo, C.E. (2006). «El ordenamiento territorial como cometido esencial del Estado». Revista de Derecho Público (29), 79-80.

Gorosito ZuluagA, R. (1996). La regularización de los asentamientos como política social y del Estado. En: Asentamientos irregulares. Montevideo, Uruguay: MVOTMA.

Gorosito ZuluagA, R., y Ligrone Fernández, P. (2009). Ordenamiento territorial y desarrollo sostenible: Ley fundante 18.308. Montevideo: La Ley Uruguay.

LEBRET, L.J. (1960). Dinámica concreta del desarrollo. Barcelona: Herder.

Ley 16.603 (1994). Código civil. Recuperado de https://www.impo.com.uy/ bases/codigo-civil/16603-1994.

Ley 18.308 (2008). «Ordenamiento territorial y desarrollo sostenible». Diario Oficial, $27515,642 \mathrm{~A}-654 \mathrm{~A}$.

Maldonado. Intendencia Municipal, Universidad de la República (URuguay). Facultad de

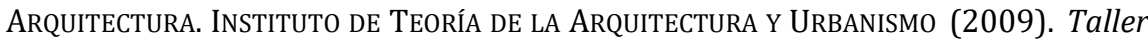
territorial departamental. Talleres territoriales de Maldonado «Construyamos el territorio departamental entre todos», Maldonado, 2006-2008. (Taller territorial microrregión; 0). Montevideo, Uruguay: FARQ, Intendencia Municipal de Maldonado.

OEA (1933). Convención sobre los Derechos y Deberes de los Estados, 7. (Montevideo, dic.). Recuperado de http://bibliotecajb.org/Portals/0/docs/dinternacional/ 19.pdf.

ONU (s.f.). Programa 21. Recuperado de http://www.un.org/spanish/ esa/sustdev/agenda21/agenda21sptoc.htm.

ONU (1987). Informe de la Comisión Mundial sobre el Medio Ambiente y el Desarrollo. Recuperado de http://www.un.org/es/comun/docs/?symbol=A/RES/42/187.

ONU (2005). El Derecho del Mar: Obligaciones de los Estados Partes conforme a la Convención de las Naciones Unidas sobre el Derecho del Mar e Instrumentos Comple- 
mentarios. Nueva York: Naciones Unidas. Recuperado de http:// www.un.org/Depts/los/doalos_publications/publicationstexts/E.04.V.5_s.pdf.

Real Academia EsPañola (2001). Diccionario de la lengua española (22. a ed.). Madrid: Espasa-Calpe.

UrRuZola, J.P. (2009). «Comentarios. A propósito de la nueva Ley de Ordenamiento Territorial y sus directrices nacionales». Pampa: Revista Interuniversitaria de Estudios Territoriales, 5(5), 107-121. http://bibliotecavirtual.unl.edu.ar:8180/ publicaciones/bitstream/1/2885/1/Pampa_5_5_2009_pag_107_121.pdf.

Uruguay. Cámara de Senadores, Comisión de Vivienda y Ordenamiento Territorial (2006). Versión taquigráfica de la sesión del día 27 de setiembre de 2006. Carpeta 631/2006, distribuido 1184. Montevideo: CSS. Recuperado de: http://www0.parlamento.gub.uy/distribuidos/AccesoDistribuidos.asp?Url=/dis tribuidos/contenido/senado/s20061184.htm.

Uruguay. Poder Legislativo, Cámara de Senadores, Comisión de Vivienda y Ordenamiento Territorial (2007). Ordenamiento territorial y desarrollo sostenible. Regulación. Asunto 30735. Carpeta 631/2006. Montevideo: Parlamento del Uruguay. Recuperado de: https://parlamento.gub.uy/documentosyleyes/ficha-asunto/ 30735/tramite. 